SLPPLEMENTARY NOTE ON THE ANTHOMYIID GENLS PHYLLOGASTER (DIPTERA).

BY J. R. MALLOCH, URBANA, ILL.

Since sending my paper, on the genus Phyllogaster, which appeared in Can. Ent., XLIX, p. 227-228, 1917, I have read C. W. Johnson's paper in the April number of the same volume, in which he describes a new species of this genus under the name robustus. An examination of paratypes of robustus discloses the fact that in addition to the difference in size between the species and cordyluroides the male may readily be separated from the latter and also from littoralis by the presence of a large number of strong bristles on the basal dorsal segment of the hypopygium (two in the others) and the much largér pulvilli which exceerl in length that of the apical tarsal joint, whereas in the others they are much shorter than it. The female of robustus has two thorns on apical abdominal segment, littoralis has four, the female of cordyluroides is unknown to me. As in cordyluroides the third vein of the wing is bare in robustus.

\title{
THE GENUS HADRONEMA UHL. (MIRIDE; HETEROPTERA.)
}

BY EDMUND H. GIBSON, U. S. BUREAC OF EXTOMOLOGY.

The flower bugs of the genus Hadronema Uhl. constitute an interesting little group closely allied to the genus Lopedia Lhi. species of which are known to most collectors of insects, such as the common Phlox bug. Those of Hadronema may be distinguished from the species of Lopedia by the fact that the base of the vertes is strongly carinate across its whole width.

Most of the species are of western occurrence, though, militaris Lhl., the haploty pe of the genus, is distributed over the entire United States and Southern Canada. Little is known of the economic importance of the species, and in all probability they are but little restricted in food preferences.

The genus belongs to the division Lopediaria Van D. of the tribe Orthotylini Van D, and was characterized by Uhler as follows: Aspect of Lopus, cranium somewhat convex, face almost rertical, eyes prominent, oval, almost vertical; oćciput with a March, 1918 